\title{
EDITORIAL
}

\section{Regulación de la Investigación biomédica: Más que normas, una cultura.}

Regulation of biomedical research: More than norms, a culture

Filiación:

1. Unidad Medicina Interna, Pfizer Biopharmaceutical Group América Central y Caribe. San José, Costa Rica.

Correspondencia: $\square$ Daniel Bustos-Montero. Correo electónico: daniel.bustos@pfizer. com

Forma de citar: Bustos Montero D. Regulación de la investigación biomédica: Más que normas, una cultura. Rev Ter. 2019;13(1):4-5.

Financiamiento:

Autofinanciado

Conflictos de Interés:

El autor declara no tener conflictos de interés en la presente publicación

Fecha de recepción: 6 de enero de 2019

Fecha de aceptación: 24 de enero de 2019
Daniel Bustos-Montero ${ }^{1} \square$

Desde la aceptación del Código de Núremberg ${ }^{1}$ de 1947 como punto de partida de la regulación de la investigación con seres humanos y la consecuente reinterpretación realizada por la Asociación Médica Mundial en 1964, hoy día conocida como la Declaración de Helsinki2, muchos han sido los esfuerzos realizados por los diferentes organismos internacionales y por los mismos países en su individual gestión, para poder contar con un marco regulatorio estandarizado que proteja a las personas participantes en una investigación y que, a la vez, promueva y permita que esta actividad se integre como el motor del desarrollo de la salud en el mundo ${ }^{1-7}$.

Pero, ¿por qué es importante regular la investigación con seres humanos? En un principio, esta fue la interrogante planteada por los diversos actores involucrados, especialmente por los investigadores, que con el desarrollo y mejor entendimiento del tema, propiciaron discusiones de altísimo nivel que fueron nutriendo el marco regulatorio actual.

La justificación de esta necesidad de regular la actividad investigativa, queda de manifiesto en la pauta 1 de las Pautas Éticas Internacionales para la Investigación y Experimentación en Seres Humanos de CIOMS de 2002, en la que se señala lo que a continuación se transcribe:

La justificación ética de la investigación biomédica con seres humanos radica en la expectativa de descubrir nuevas formas de beneficiar la salud de las personas. La investigación puede justificarse éticamente sólo si se realiza de manera tal que respete y proteja a los sujetos de esa investigación, sea justa para ellos y moralmente aceptable en las comunidades en que se realiza. ${ }^{5}$

Así las cosas, resulta lógico el pensar que para que las regulaciones en investigación con seres humanos logren su cometido deberán, obligatoriamente, cumplir con tres características esenciales: 
1. Capacidad de adaptación, que permita el análisis de determinada situación en el contexto de la sociedad y su ulterior aplicación con base en los resultados de dicha discusión.

2. Trascendencia, es decir que se evite la normativización de la investigación, en su lugar enfocarse en los detalles que realmente tengan un impacto para guiar el desarrollo de esta actividad.

3. Sentido común, la característica más importante de toda praxis humana.

Considerando que cualquier actividad que involucre el estado de salud de un ser humano siempre traerá consigo un conflicto ético, no cabe duda que el marco normativo internacional dista mucho de la perfección; sin embargo, constituye la base para salvaguardar la dignidad y el bienestar de las personas que participan en una investigación.

Sin embargo, sería un grave error si olvidamos que las regulaciones, por sí solas, nunca podrán lograr su objetivo. Es vital el compromiso de todos los profesionales en ciencias de la salud involucrados en este tema, así como una sensibilización moral y ética para poder lograr su efectiva implementación. Solo así podremos lograr la efectiva protección de las personas que participan en un estudio de investigación.

\section{Referencias}

1. United States Holocaust Memorial Museum [Internet]. Washington: USHMM; [citado el 30 de abril de 2001]. Nuremberg Code [aprox. 3 pantallas]. Disponible en: https://www.ushmm.org/ information/exhibitions/online-exhibitions/special-focus/doctors-trial/nuremberg-code

2. Asociación Médica Mundial [Internet]. Francia: WMA; 2017. Declaración de Helsinki 1964 de la AMM. Principios éticos para las investi- gaciones médicas en seres humanos [aprox. 5 pantallas]. Disponible en: https://www.wma. net/es/policies-post/declaracion-de-helsinki-de-la-amm-principios-eticos-para-las-investigaciones-medicas-en-seres-humanos/

3. National Commission for the Protection of Human Subjects of Biomedical and Behavioral Research. The Belmont Report: Ethical Principles and Guidelines for the Protection of the Human Subjects of Research. USA: The National Commission; 1979.

4. Beauchamp T, Childress J. Principles of Biomedical Ethics. 5a ed. New York: Oxford University Press; 2001.

5. Consejo de Organizaciones Internacionales de las Ciencias Médicas. Pautas Éticas Internacionales para la Investigación Biomédica en Seres Humanos. Ginebra: CIOMS; 2002.

6. Consejo de Organizaciones Internacionales de las Ciencias Médicas. Pautas Internacionales para la evaluación ética de los estudios epidemiológicos. Ginebra: CIOMS; 1991

7. International Conference on Harmonisation of Technical Requirements for Registration of Pharmaceuticals for Human Use. Guidelines for Good Clinical Practice: Consolidated Guidance. USA: Federal Register; 1997. 